\title{
Identification of Fungal Communities in Producing Compost by Windrow Method
}

\author{
Rouhullah Dehghani ${ }^{1}$, Mohammad Ali Asadi ${ }^{2}$, Esmail Charkhloo ${ }^{1 *}$, Gholamreza Mostafaie ${ }^{1}$, \\ Mohmoud Saffari ${ }^{3}$, Gholam Abbas Mousavi ${ }^{4}$, Mohammad Pourbabaei ${ }^{3}$
}

${ }^{1}$ Department of Environmental Health, Faculty of Health, Kashan University of Medical Sciences, Kashan, I.R. Iran; ${ }^{2}$ Department of Laboratory Medicine, Faculty of Paramedicine, Kashan University of Medical Sciences, Kashan, I.R. Iran; ${ }^{3}$ Department of Microbiology and Immunology, Kashan University of Medical Sciences, Kashan, I.R. Iran; ${ }^{4}$ Department of Biostatistics and Public Health, Kashan University of Medical Sciences, Kashan, I.R. Iran.

Email: *echarkhloo@yahoo.com

Received September $7^{\text {th }}, 2011$; revised October $15^{\text {th }}, 2011$; accepted November $17^{\text {th }}, 2011$

\begin{abstract}
Considering the importance of fungal genera in producing compost from piling organic matter or biodegradable waste, this study aimed to identify the fungal species and their negative effect on human health during the compost production by windrow method. In this descriptive study, 99 compost samples were collected from the composting research site at Kashan University of medical sciences within 63 days from Oct 3 to Dec 4, 2010. Sixty-six samples were cultured to determine the fungal species and 33 samples were transferred to the laboratory to determine the physical and chemical parameters. Twenty-five fungal species were identified during the compost process including 15 saprophytes, 8 dermatophites, 1 opportunistic and 1 yeast fungi. Identified fungal species during the compost process according to their frequencies were Aspergillus spp (34.45\%), Microsporium spp (18.89\%), Trichophyton spp (8.89\%), Yeast sp (6.67\%), Mucor sp (5.56\%), Penicillium sp (4.45\%), Rhizopus sp (4.45\%), Fusarium sp (3.34\%), Cladosporium sp (3.34\%), Curvularia sp (3.34\%) and also other fungal species (6.62\%), respectively. Considering the presence of various pathogenic fungi during the composting process, the employees of the compost factory should use individual protective devices and also due to the presence of 11 fungal species in the mature compost and their pathogenic effect, preventive measures should be taken by persons involved in the production of compost especially farmers, in order to prevent successive inhalation of spores.
\end{abstract}

Keywords: Compost; Windrow; Method; Fungal Species

\section{Introduction}

Out of about 250,000 fungal species which have been known so far, only less than 200 species identified that are human pathogens. The majority of Most human pathogenic fungi can enter from the environment into the host body through inhalation, swallowing and by oral contact with compost in case of skin damage (wound). Most of them can be found in the environment, air, soil, decaying vegetables and fruits, waste, wastewater [1]. Rotting vegetables and fruits are the main food sources of fungi, containing essential nutrients (e.g. primidone and thiamine) to grow fungi [2]. During a compost process which is an aerobic process, the organic matter of waste can be converted into useful organic manure by microorganisms [3]. This widespread technology destroys pathogens and converts potentially harmful waste products into an

${ }^{*}$ Corresponding author. odorless and inoffensive material and it may also have more positive effects on the physical, chemical and biological characteristics of soil by increasing vegetation, a protective layer to prevent soil erosion [4-6]. Compost happens either aerobically (with oxygen) or anaerobically (without oxygen). The most efficient and common form of composting is the aerobic windrow composting [7]. Composting by the windrow method based on temperature can be divided into four different stages: the mesophilic, thermophilic, cooling and maturation stages [8].

Organisms that play a major role in the composting process regarding their frequency are bacteria, fungi, actinomycetes and animal materials, respectively [9]. The biomass ratio of fungi to prokaryotes in compost is about 2:1. In addition, fungi existing in compost use many carbon sources, mainly lignocellulosic polymers and can survive in extreme conditions. They mainly are responsible for compost maturation. Fungal genera (e.g. Aspergillus, Penicillium, Fusarium, Acremonlum and Cladosporium) 
are dominant in the compost process [5,10].

There are parameters that play an important role in the frequency of fungal species during a composting process including temperature, moisture, $\mathrm{C} / \mathrm{N}$ ratio, $\mathrm{pH}$ and required oxygen to maintain the aerobic conditions. Two parameters of moisture and $\mathrm{pH}$ are more effective in fungal activities $[7,11]$. The optimum temperature range during the composting process is $37^{\circ} \mathrm{C}-60^{\circ} \mathrm{C}$; the optimum moisture range is $40 \%-60 \%$; the optimum $\mathrm{C} / \mathrm{N}$ ratio $20-25: 1$; the optimum $\mathrm{pH}$ range is 6.0 to 8.0 and the required oxygen to maintain an aerobic condition is $21 \%$ [12].

One of the main problems of producing compost is the growth of fungal pathogens during the compost process. Considering that the incidence of fungal infections has been increasing in human especially in patients of cancer, tuberculosis, diabetes, immunodeficiency syndrome (AIDS) and in patients under the treatment with medications which suppresses the immune system and also patients who receive antibiotic and anti-metabolic agents, the importance of identifying these fungal species is highlighted [2]. Fungal genera have been found in soil and waste all over the world but the frequencies of them varies among different regions in terms of the climatic conditions which fungi require in order to grow and survive [13]. Hence, the climatic conditions should be considered during the composting process.

Producing compost from municipal solid waste is a common process in all countries like Iran. Solid waste generation rate in Kashan city (Isfahan province, it is situated in the center of Iran with a population of approximately 220,000 people) is about 160 tons per day; $71.66 \%$ (114.66 ton per day) of them including the disposable materials to produce compost [14]. Thus producing compost can solve solid waste management problems in this city. Considering the large amounts of municipal waste in this city, this study aimed to identify the fungal communities and their harmful and pathogenic effects on human health in producing compost by windrow method. Therefore, different organizations involved with solid waste as well as waste disposal systems can benefit from the results of this study.

\section{Methods and Materials}

At first, with coordination of Kashan municipality, 4.5 tons of raw materials and household waste were transported to the waste research site of Kashan University of medical sciences and then compostable ingredients separated and the size of fragmented waste ingredients were smaller than $5 \mathrm{~cm}$; they were thrown in the place in a dome form and gradually built up a windrow pile of $1.5 \mathrm{~m}$ in height and $2.5 \mathrm{~m}$ in width. Various parameters of compost production were measured and logged during 63 days from Oct 3 to Dec 4, 2010. Sampling of the com- post pile was done 4 times, at first two weeks then 1 time, at the next weeks, and a total of 11 times. During 63 days, 66 samples were cultured to determine the fungal communities and also other 33 samples transferred to the laboratory to determine the physical and chemical parameters. Samples were taken from the surface and two different compost depths ( 3 and $50 \mathrm{~cm}$ ) to determine their fungal communities and were stored in a sterile plastic container, then they were divided into smaller parts (subsamples) by a sterile scalpel and cultured in two culture media of Sabouraud dextrose agar (S) and Sabouraud dextrose agar + Cycloheximide + Chloramphenicol (SCC). The culture media were examined after 48 hours to 1 week (168 hours) incubation and then Lams were provided from cultured samples to identify microscopically. The obtained results were recorded on checklists. Data were analyzed and classified and then tables and figures were drawn. Stratified sampling which is a modified method of compound sampling was applied to determine the physical and chemical parameters of the waste samples. A thermometer was placed into compost pile to determine its temperature and after several minutes, the compost temperature was recorded and the compost thermometer was also used to measure the areas surrounding the compost pile [15]. The moisture content of the compost samples determined in ovens at $105^{\circ} \mathrm{C}$ for 24 - 48 hours and the slurry with a ratio of 1:10 was obtained from the compost samples and then the $\mathrm{pH}$ measurement was done using $\mathrm{pH}$ meter [3]. To determine the $\mathrm{C} / \mathrm{N}$ ratio, total carbon content of the samples determined through combustion in ovens at $750^{\circ} \mathrm{C}$ for 2 hours and total nitrogen analysis was performed by Kjeldahl method [16]. To provide necessary oxygen in compost pile during the process, it was turned by a hand crank once a week at first month, and once per two weeks at the second month [1].

\section{Results}

The results of this study indicated that 25 fungal species were identified during the compost process including 15 saprophytes, 8 dermatophites, 1 opportunist and 1 yeast fungi. Identified fungal species during the compost process according to their frequencies were Aspergillus spp (34.45\%), Microsporium spp (18.89\%), Trichophyton spp (8.89\%), Yeast sp (6.67\%), Mucor sp (5.56\%), Penicillium sp (4.45\%), Rhizopus sp (4.45\%), Fusarium $s p$ (3.34\%), Cladosporium sp (3.34\%), Curvularia sp (3.34\%) and also other fungal species (6.62\%), respectively (Figure 1).

The highest fungal variety was seen in 56th and 63rd day of composting process. A. niger fungus was seen in all the stages of sampling and fungal species (e.g. A. flavus, Trichophyton ajelloi, A. niger, Microsporium cookei, A. fumigatus, other Aspergillus sp, Candida sp, Mucor sp, 
Yeast sp, Rhizopus sp and Nigrospora $s p$ ) were observed at the last day of the compost process in mature compost (Table 1).

Most fungal species were taken from the compost pile at depth of $3 \mathrm{~cm}$ with frequency of $47.8 \%$ and the lowest species were taken at $50 \mathrm{~cm}$ depth with frequency of $14.45 \%$. Moreover, $70 \%$ of fungal species were seen in culture medium of S and only $30 \%$ of them were seen in SCC culture medium (Table 2).
In addition, the results of this study showed that the compost pile moisture content at first was 68\% and reached $73 \%$ at the fifth day that decreased after aeration and reached $56 \%$ in ninth day of sampling (Figure 2). The initial $\mathrm{pH}$ was 5.5 that gradually increased to the maximum level 8.4 in 56th day and it decreased to 7.72 at the last day of sampling (Figure 3). Physical and chemical parameters during the compost process in terms of days of composting( Table 3).

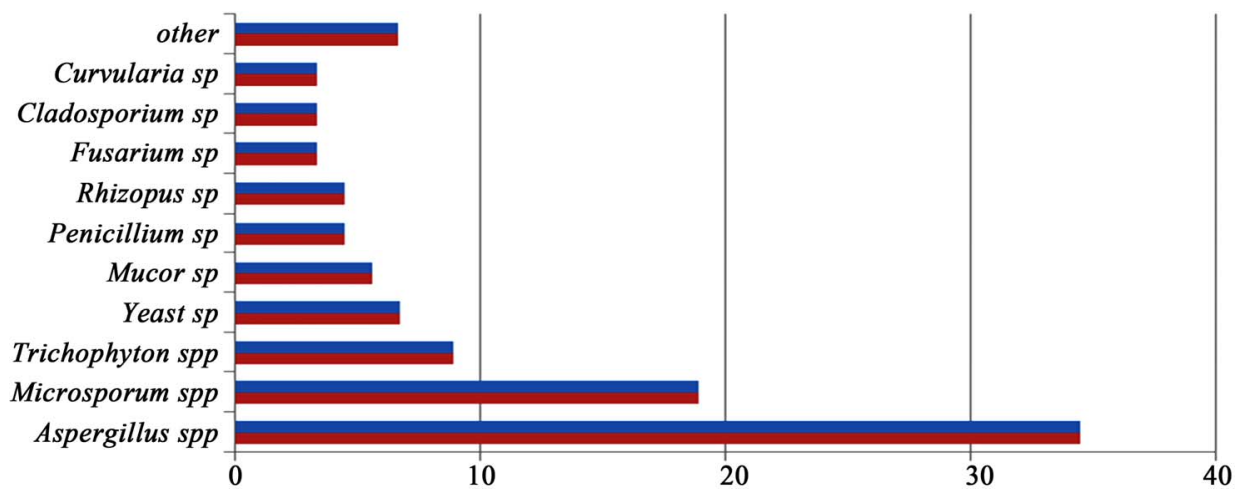

Figure 1. Frequency percentages of fungal species in compost pile.

Table 1. Frequency distribution of fungal species in terms of the days of sampling of the compost.

\begin{tabular}{|c|c|c|c|c|c|c|c|c|c|c|c|c|}
\hline \multirow{2}{*}{ Fungal species } & \multicolumn{12}{|c|}{ Days } \\
\hline & 1 & 5 & 9 & 13 & 21 & 28 & 35 & 42 & 49 & 56 & 63 & total \\
\hline Aspergillus flavus & + & + & - & - & + & - & - & + & - & + & + & 6 \\
\hline Fusarium sp & + & - & - & + & - & - & - & - & - & + & - & 3 \\
\hline Trichophyton ajelloi & + & - & + & - & - & - & + & + & - & - & + & 5 \\
\hline Cladosporium sp & + & - & + & - & - & + & - & - & - & - & - & 3 \\
\hline A. terreus & - & + & + & - & - & + & + & - & - & - & - & 4 \\
\hline Microsporium gypseum & + & + & - & + & + & + & - & - & + & - & + & 7 \\
\hline Curvularia sp & - & + & + & - & - & - & - & - & - & + & - & 3 \\
\hline M. fulvum & - & + & - & + & - & - & - & - & + & + & - & 4 \\
\hline A. niger & + & + & + & + & + & + & + & + & + & + & + & 11 \\
\hline M. cookei & - & + & + & + & - & + & + & - & - & - & + & 6 \\
\hline A. fumigatus & - & - & + & - & + & + & + & + & - & + & + & 7 \\
\hline Helminthosporium & + & - & - & - & - & - & - & - & - & - & - & 1 \\
\hline Other Aspergillus sp & - & - & - & - & - & - & - & - & + & + & + & 3 \\
\hline Candida sp & - & - & - & - & - & - & - & - & - & - & + & 1 \\
\hline T. verrucosum & - & - & - & - & - & - & + & - & - & - & - & 1 \\
\hline Penicillium sp & + & + & + & - & + & - & - & - & - & + & - & 4 \\
\hline Mucor sp & - & - & - & + & - & - & + & + & + & - & + & 5 \\
\hline T. mentagrophyes & - & - & - & - & - & - & -- & - & + & - & - & 1 \\
\hline Acremonium sp & - & - & - & + & - & - & - & - & - & - & - & 1 \\
\hline Scopullariopsis sp & - & - & - & + & - & - & - & - & - & - & - & 1 \\
\hline T. Menta var quincheanum & - & - & - & - & - & - & - & - & - & + & - & 1 \\
\hline Yeast sp & - & - & + & - & + & + & - & + & - & + & + & 6 \\
\hline Rhizopus sp & - & - & - & - & + & - & - & + & + & - & + & 4 \\
\hline Alternaria sp & - & - & - & - & - & + & - & - & - & - & - & 1 \\
\hline Nigrospora sp & - & - & - & - & - & - & - & - & - & - & + & 1 \\
\hline Total & 8 & 8 & 8 & 9 & 6 & 8 & 7 & 8 & 6 & 11 & 11 & 90 \\
\hline
\end{tabular}


Table 2. Frequency distribution of fungal species in terms of sampling from the depth of compost pile.

\begin{tabular}{|c|c|c|c|c|c|c|c|}
\hline \multirow{2}{*}{ Fungal species } & \multicolumn{2}{|c|}{ Surface } & \multicolumn{2}{|c|}{3 cm depth } & \multicolumn{2}{|c|}{$50 \mathrm{~cm}$ depth } & \multirow{2}{*}{ Total } \\
\hline & $\mathrm{S}$ & SCC & $\mathrm{S}$ & SCC & $\mathrm{S}$ & SCC & \\
\hline Aspergillus flavus & 2 & - & 3 & - & 1 & - & 6 \\
\hline Fusarium sp & 1 & - & 2 & - & - & - & 3 \\
\hline Trichophyton ajelloi & - & 1 & - & 3 & - & 1 & 5 \\
\hline Cladosporium sp & 1 & - & 1 & - & 1 & - & 3 \\
\hline A. terreus & 2 & - & 2 & - & - & - & 4 \\
\hline Microsporium gypseum & - & 2 & - & 4 & - & 1 & 7 \\
\hline Curvularia sp & 1 & - & 1 & - & 1 & - & 3 \\
\hline M. fulvum & - & 2 & - & 2 & - & - & 4 \\
\hline A. niger & 4 & - & 5 & - & - & 2 & 11 \\
\hline M. cookei & - & 2 & - & 3 & - & 1 & 6 \\
\hline A. fumigatus & 4 & - & 2 & - & 1 & - & 7 \\
\hline Helminthosporium & 1 & - & - & - & - & - & 1 \\
\hline Other Aspergillus sp & 1 & - & 2 & - & - & - & 3 \\
\hline Candida sp & - & - & - & 1 & - & - & 1 \\
\hline T. verrucosum & - & - & - & 1 & - & - & 1 \\
\hline Penicillium sp & 2 & - & 2 & - & - & - & 4 \\
\hline Mucor sp & 2 & - & 2 & - & - & - & 4 \\
\hline T.mentagrophyes & - & - & 1 & - & - & - & 1 \\
\hline Acremonium sp & 1 & - & - & - & - & - & 1 \\
\hline Scopullariopsis sp & - & - & 1 & - & - & - & 1 \\
\hline T. Menta var quincheanum & - & - & 1 & - & - & - & 1 \\
\hline Yeast sp & 3 & - & 2 & - & 1 & - & 6 \\
\hline Rhizopus sp & 2 & - & 1 & - & 1 & - & 4 \\
\hline Alternaria sp & - & - & 1 & - & - & - & 1 \\
\hline Nigrospora sp & 1 & - & - & - & - & - & 1 \\
\hline Total & 28 & 7 & 28 & 15 & 7 & 5 & 90 \\
\hline
\end{tabular}

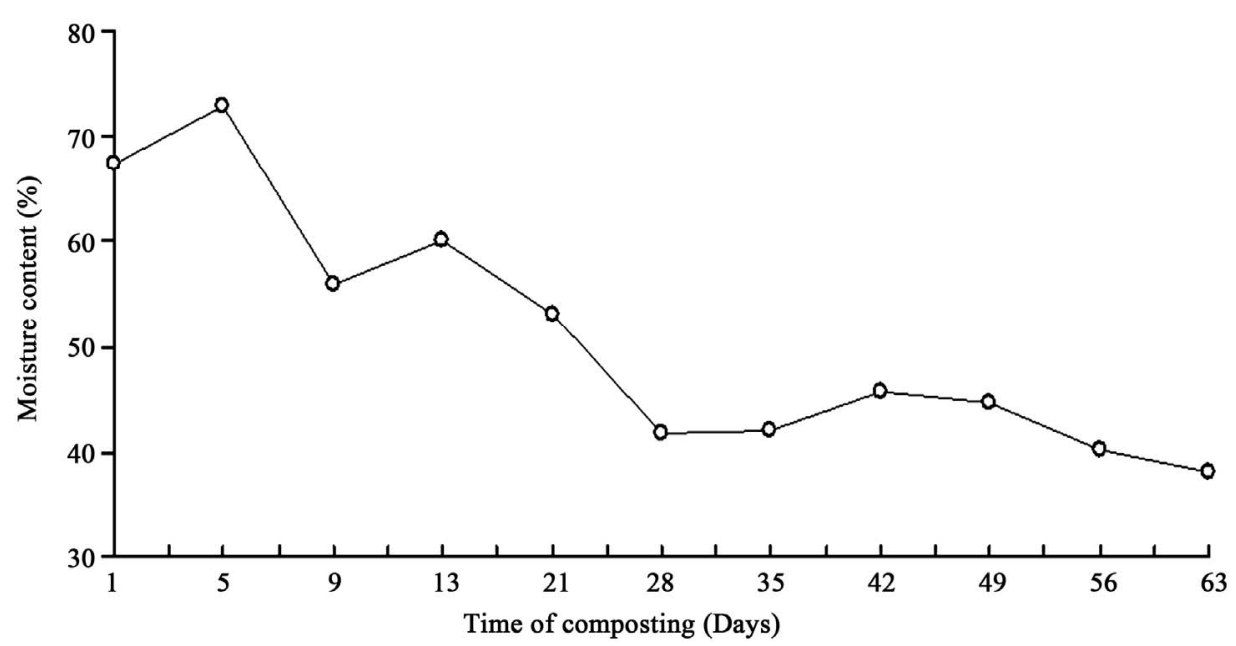

Figure 2. The moisture variations in terms of the days of composting. 


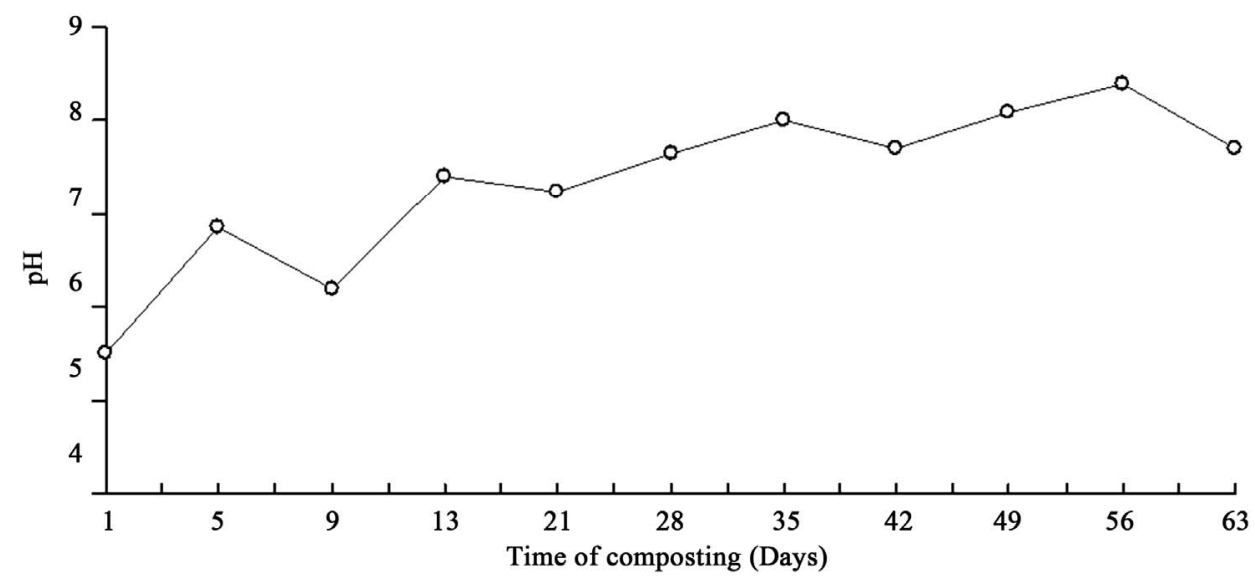

Figure 3. The $\mathrm{pH}$ variations in terms of the days of composting.

Table 3. Physical and chemical parameters during the compost process in terms of days of composting.

\begin{tabular}{lccccccccccc}
\hline \multirow{2}{*}{ Parameters } & \multicolumn{10}{c}{ Days } \\
\cline { 2 - 11 } & $\mathbf{1}$ & $\mathbf{5}$ & $\mathbf{9}$ & $\mathbf{1 3}$ & $\mathbf{2 1}$ & $\mathbf{2 8}$ & $\mathbf{3 5}$ & $\mathbf{4 2}$ & $\mathbf{4 9}$ & $\mathbf{5 6}$ & $\mathbf{6 3}$ \\
\hline Temperature $\left(^{\circ} \mathbf{C}\right)$ & 38 & 48 & 65 & 60 & 45 & 43 & 40 & 42 & 39 & 37 & 26 \\
Water Content & 67.5 & 73 & 55.8 & 60 & 53 & 41.8 & 42 & 45.77 & 44.6 & 40.1 & 38 \\
$\mathbf{p H}$ & 5.5 & 6.85 & 6.2 & 7.4 & 7.25 & 7.65 & 8 & 7.72 & 8.08 & 8.4 & 7.7 \\
$\mathbf{C} / \mathbf{N}$ & 35 & 34 & 29 & 27.8 & 28.6 & 22 & 20.7 & 18.2 & 15 & 13.6 & 12.5 \\
\hline
\end{tabular}

\section{Discussion}

Identification of fungal diversity is very necessary in order to determine the fungi harmful to humans, animals and plants and also to optimize compost quality standards [5]. The presence of 25 fungal species during the composting process indicates there are a large number of these fungal species. A. niger species was seen in all of the sampling stages and fungal species (e.g. A. flavus, Trichophyton ajelloi, A. niger, Microsporium cookei, A. fumigatus, other Aspergillus sp, Candida sp, Mucor sp, Yeast $s p$, Rhizopus $s p$ and Nigrospora $s p$ ) were seen in the last day in the mature compost. In the study of Anastasi et al. (2005) on the fungal population during the composting process in Turin city of Italy, fungal genera (e.g. Fusarium, Cladosporium, Acremonium, Penicillium, Rhizopus) and different related species of Aspergillus fungus especially $A$. fumigatus were identified [5]. It can be claimed that the results of this study are consistent with those of Anastasi et al. In another study carried out by Rebollido et al. (2007) in Havana city of Cuba on the compost of municipal waste, fungal genera (e.g. Penicillium Alternaria, Aspergillus, richoderma, Ulocladium) were identified [3]. It is worth mentioning that two fungal genera of Trichoderma and Ulocladium were not identified in the present study; one of the reasons that these two fungal species were not seen in this study is because of different climate conditions in Kashan city (dry and hot weather) and Havana city.

The results of this study revealed that one of the most frequent and medically important fungi is A. fumigatus and one of the problems that occurred during the compost process is emitting of from some fungi particularly A. fumigatus that the bioaerosols can contaminate the areas surrounding the compost especially while turning compost pile for aeration [17,18]. Moreover, A. fumigatus may cause serious allergic diseases in people who are genetically predisposed to these diseases [19].

The bioaerosols concentrations emitted from $A$. fumigatus and thermophilic actinomycetes were measured in air downwind $500 \mathrm{~m}$ from an outdoor composting site [20]. So, the distance of composting site from the places where people live should be observed. Fungal genus of Mucor can be very dangerous and even can lead to death especially in patients with suppressed immune system after organ transplantation and diabetic patients. Fusarium is known as a saprophytic fungus can cause keratitis and onychomycosis. Six hundred species of Aspergillus fungus have been identified so far which can cause infections of internal organs and skin, and can damage human eye, ear and fingernails. Toxic chemical products produced by these fungal species mostly lead to the allergic reactions. A. flavus species produces poisonous substance named Aflatoxin and can cause the liver cancer. The first and the second fungi which can cause eye infections are 
A. fumigatus and Fusarium solani, respectively. In addition, some of the strains of this fungus can cause mycetoma which is one of the fungal diseases can produce profound disability in patients and in some cases, surgery and cutting out an organ may be the only treatment. Penicillium marneffei causes Penicilliosis in humans and Scopulariopsis is a causative agent of Onychomycosis (nail infection), keratitis and otitis. Cladosporium is other fungus which grow in a compost sample; 500 species of Cladosporium have been identified which some of them may cause Chromoblastomycosis. All of the dermatophites which exist and grow in the compost can cause human Alopecia [21]. It is worth mentioning that the above-mentioned fungal communities are related to soil sample and other products like compost. Considering the importance of these fungal communities regarding their pathogenic and harmful effects on humans, hygienic measures are recommended during the compost production or while filling the pots and vases with composted soil inside the home.

In this study, the moisture in the beginning of the composting process was $68 \%$ reached $73 \%$ in fifth day then after aeration decreased to $56 \%$ in ninth day. Thus, the composting process was not impaired. In some cases, the compost pile may lose its moisture because of increasing the heat due to microbial growth [3]. At the beginning of the compost process, $\mathrm{pH}$ level was 5.5 because of the acid-forming bacteria existing in compost pile. Synthesis of the organic materials increases the microbial population that these bacteria uses acids as substrate which causes the $\mathrm{pH}$ increase to about 8 - 9 and the compost pile become alkaloid [22]. The $\mathrm{pH}$ level in 56th day reached to the maximum level 8.4 but in the last day sampling reached the optimum level 7.7. The $\mathrm{pH}$ drop in the composting process may be attributed to ammonia production resulting from the influence of bacteria on the nitrogen of organic materials (Ammonification) or because of the conversion of organic materials to minerals by microorganisms (mineralization) [3].

\section{Conclusion}

According to the results of this study, fungal species including saprophytes and dermatophites were identified during the compost process. Considering that some of these fungal species such as A. fumigatus are human pathogens and can cause serious diseases in employees who are involved in the production of compost, preventive measures like applying protective equipments (e.g. mask with P3 filter, appropriate gloves and other necessary equipments) should be taken by the employees involved in the compost production, in order to prevent successive inhalation of spores. Regarding the importance of the composting sites, finding the suitable loca- tion for producing compost and also efficient management during the composting process can be effective to improve the individual health and hygienic conditions of the composting sites.

\section{Acknowledgements}

This study has been done with the financial support of research Deputy of Kashan University of medical sciences and the research credit number 8939. We are indeed thankful for the cooperation from the authorities of the health faculty and the medical laboratory, Mrs. Sabaghian, Mrs. Motamed alroaya and Mr. Hasanzadeh in this study.

\section{REFERENCES}

[1] M. D. Richardson and D. W. Warnock, "Fungal Infection Diagnosis and Management," 2nd Edition, Black Well, Oxford, 1997.

[2] C. C. Kibbler, D. W. R. Mackenzie and F. C. Odds, "Principles and Practice of Clinical Mycology," Wiley. Hoboken, 1996.

[3] R. Rebollido, J. Martinez, Y. Aguilera, K. Melchor, I. Koerner and R. Stegmann, "Microbial Populations during Composting Process of Organic Fraction of Municipal Solid Waste," Applied Ecology and Environmental Research, Vol. 6, No. 3, 2008, pp. 61-67.

[4] V. A. Labud, L. G. Semenas and F. Laos, "Diptera of Sanitary Importance Associated with Composting of Biosolids in Argentina,” Revista de Saúde Pública, Vol. 37, No. 6, 2003, pp. 722-728. doi:10.1590/S0034-89102003000600006

[5] A. Anastasi, G. C. Varese and V. F. Marchisio, "Isolation and Identification of Fungal Communities in Compost and Vermicompost," Mycologia, Vol. 97, No. 1, 2005, pp. 33-44. doi:10.3852/mycologia.97.1.33

[6] R. C. Brandli, T. D. Bucheli, T. Kupper, R. Furrer, F. X. Stadelmann and J. Tarradellas, "Persistent Organic Pollutants in Source-Separated Compost and Its Feedstock Materials-A Review of Field Studies,” Journal of Environmental Quality, Vol. 34, No. 3, 2005, pp. 735-760.

[7] G. Tchobanoglous, H. Theisen and S. Vigil, "Integrated Solid Waste Management," McGraw-Hill, New York, 1993.

[8] K. Ishii, M. Fukui and S. Takii, "Microbial Succession during a Composting Process as Evaluated by Denaturing Gradient Gel Electrophoresis Analysis,” Applied Microbiology, Vol. 89, No. 5, 2000, pp. 768-777. doi:10.1046/j.1365-2672.2000.01177.x

[9] G. Tchobanoglous and F. Kreith, "Handbook of Solid Waste Management,” McGraw-Hill, New York, 2002.

[10] J. Hultman, T. Vasara, P. Partanen, J. Kurola, M. H. Kontro, L. Paulin, P. Auvinen and M. Romantschuk, "Determination of Fungal Succession during Municipal Solid Waste Composting Using a Cloning-Based Analysis,” Applied Microbiology, Vol. 108, No. 2, 2010, pp. 472- 


\section{7. doi:10.1111/j.1365-2672.2009.04439.x}

[11] M. Grigatti, L. Cavani and C. Ciavatta, "The Evaluation of Stability during the Composting of Different Starting Materials: Comparison of Chemical and Biological Parameters,” Chemosphere, Vol. 83, No. 1, 2011, pp. 41-48. doi:10.1016/j.chemosphere.2011.01.010

[12] DSM Environmental Services, Yard Waste Composting Operator Training Manual, 2004.

www.awm.delaware.gov/.../Composting_Operator's_Man ual.pdf

[13] J. W. Rippon, "Medical Mycology the Pathogenic Fungi and the Pathogenic Action Mycetes," 3rd Edition, W. B. Saunders Co., Philadelphia, 1988.

[14] M. Ehsanifar and H. Almasi, "Investigating of Considerable Recovery and Composting of Municipal Wastes in Kashan City,” National Conference on Environment Health, 30 October-1 November 2007, Teheran, pp. 638-647.

[15] A. Ebrahimie, H. PuerAlagebanda, S. Khazaeelie, A. Shahsavary and A. Salehi, "The First Full Authority Quality Management High Fertilizer Production,” Scientific Institute Publications of Bareen Danesh Pajohan, 2008.

[16] H. Alidadi, A. A. Najafpoor and A. Parvaresh, "Determination of Carbon/Nitrogen Ratio and Heavy Metals in Bulking Agents nUsed for Sewage Composting," Pakistan Journal of Biological Sciences, Vol. 10, No. 22, 2007, pp. 4180-4182. doi:10.3923/pjbs.2007.4180.4182

[17] M. Nadal, I. Inza, M. Schuhmacher, M. J. Figueras and J.
L. Domingo, "Health risks of the Occupational Exposure to Microbiological and Chemical Pollutants in a Municipal Waste Organic Fraction Treatment Plant,” International Journal of Hygiene and Environmental Health, Vol. 212, No. 6, 2009, pp. 661-669. doi:10.1016/j.ijheh.2009.06.002

[18] O. L. Goff, B. V. Adan, H. Bacheley, J. J. Godon and N. Wery, "The Microbial Signature of Aerosols Produced during the Thermophilic Phase of Composting," Applied Microbiology, Vol. 108, No. 1, 2010, pp. 325-340. doi:10.1111/j.1365-2672.2009.04427.x

[19] M. L. Browne, G. M. Recer, L. R. Kallenbach, J. M. Melius and E. G. Horn, "A Prospective Study of Health Symptoms and Aspergillus fumigatus Spore Counts Near a Grass and Leaf Composting Facility,” Compost Science and Utilization, Vol. 9, No. 3, 2001, pp. 241-249.

[20] G. M. Recer, M. L. Browne, E. G. Horn, K. M. Hill and W. F. Boehler, “Ambient Air Levels of Aspergillus fumigatus and Thermophilic Actinomycetes in a Residential Neighborhood near a Yard-Waste Composting Facility," Aerobiologia, Vol. 17, No. 2, 2001, pp. 99-108. doi:10.1023/A:1010816114787

[21] Sh SHadzi, “Medical Mycology,” Jahad Daneshgahi Vahed IsfAhan, Tehran, 2006. www.JDISFAHAN.IR

[22] M. A. Zazouli, M. Bagheri, E. Ghahramani and M. Ghorbanian, "Compost Production Technology, Khaniran, 2009. www.khaniran.com 